\title{
Physician Shortage over the Next Years
}

\author{
Dania H Al-Jaroudi* \\ Reproductive Endocrine and Infertility Medicine Department, Saudi Arabia
}

Submission: June 15, 2017; Published: July 27, 2017

*Corresponding author: Dania H Al-Jaroudi, Reproductive Endocrine and Infertility Medicine Department, Women's Specialized Hospital, King Fahad Medical City, Kingdom of Saudi Arabia; Email: daljaroudi@kfmc.med.sa

\begin{abstract}
It may be well understood that the increased demand of physicians in the US could be explained by the increase in population growth of the United States and that the largest growth will occur in the population of over 65 years which translates into an increase in consumption of health care resources. For example, patients aged 65 years had 7.6 physician ambulatory care visits a year versus 3.3 per year for those under 65 i.e. $130 \%$ more visits. Additionally, the use of more health resources is expected to increase because of the higher expectations of the American population. On the other hand, when scrutinizing the supply of physicians, it seems that around one third of physicians currently are over the age of 55 years and who are likely to retire by the year 2020. The employment of physicians and surgeons is projected to grow 14 percent from 2014 to 2024.
\end{abstract}

\section{Introduction}

It may be well understood that the increased demand of physicians in the US could be explained by the increase in population growth of the United States and that the largest growth will occur in the population of over 65 years which translates into an increase in consumption of health care resources [1]. For example, patients aged 65 years had 7.6 physician ambulatory care visits a year versus 3.3 per year for those under 65 i.e. $130 \%$ more visits [1].

Additionally, the use of more health resources is expected to increase because of the higher expectations of the American population [1]. On the other hand, when scrutinizing the supply of physicians it seems that around one third of physicians currently are over the age of 55 years who are likely to retire by the year 2020 [2]. The new generation of physicians has new adaptations with new changes in the working hours and demands of physicians are unlikely to continue as opposed to the old generation of physicians who used to work long hours. According to statistics, the annual number of physicians retiring was 9,000 in the year 2000 and this is expected to be around 22,000 by the year 2020 , which is almost the number of new physicians who completed their graduate training in 2005 [3]. There is a fast increase in the employment of physicians and as projected by the national Bureau of Statistics for Physicians in the USA, employment of physicians and surgeons is projected to grow 14 percent from 2014 to 2024. This growth is due to an increase in demand for healthcare services by the growing and aging population [4]. Therefore, the needs of medical services are likely to increase by the year 2020 , and similarly an increasing demand of physicians [3].

Therefore, if enrollment to US medical schools is to increase in response to the growing shortage of physicians, then teaching hospitals may use the increase in U.S. graduates to reduce their reliance on international Medical Graduates (IMGs). IMGs make $25 \%$ of new physicians who enroll in the residency training in the United States each year [3].

To address the shortage of physicians, the Association of American Medical Colleges (AAMC) has looked into increasing the enrollment of US citizens in the upcoming years [5]. The (AAMC) recommended to medical schools in America that they increase the number of medical school enrollment by $30 \%$ which is approximately 5,000 graduates per year by the year 2015. The National Council on Graduate Medical Education (COGME) recommended an increase of 3,000 graduates per year by the year 2015 [5]. Additionally, for both publicly and privately insured populations, a variety of integrated care delivery models are being implemented in order to aid in integrated/holistic approaches to more targeted interventions [5] There is also an addition of physician assistance (PA) to cater for the shortage where aproximately 95,600 PAs are in the workforce in 2013 which translates to a $219 \%$ in comparison to a decade earlier [5].

There are 125 US medical schools, out of which 113 had started to increase their enrollment of medical students which represent around two thirds of the projected enrollment plan. 


\section{Global Journal of Reproductive Medicine}

The other projected plan is to increase the number of new medical schools [5].

Thirty-three of the schools with expansion plans are targeting minority groups currently under-represented in medicine, rural areas, or under-served urban communities. Medical schools expressed continued concern over the availability of clinical training sites, which was cited as a barrier to expansion [5].

The AAMC conducts annual surveys to look at other problems that might be encountered as a result of increasing medical enrollment, around half of the schools $57 \%$ had concerns on the adequacy and availability of clinical training sites and another half had concerns about the classroom and lab space. Conversely, there was no much concern on the applicant's pool [5].

The recession in the US is currently evident, therefore, medical school expansion might not be achieved by the year 2017; however most of the expansion plans are expected to be sponsored at a public level. Liaison Committee on Medical Education (LCME) has accredited 125 schools which is anticipated to fulfill around $76 \%$ of the growth anticipated in 2013 thus the remaining $24 \%$ is still awaiting accrediting process [5]. The main goal of increasing the physicians supply is to aid in access to medical services. This will translate into a further need by the graduate medical education (GME) to increase medical graduates. A third of an increase to the first year medical school enrollment in comparison to the year 2002, means a $5000 \mathrm{MD}$ graduates have to enter the GME to attain a license to practice [5]. Therefore there is an increasing demand on the GME to increase their current positions. Additionally, if GME slots are not increased at the same rate as medical school enrollment increases, some U.S. medical school graduates may find themselves without a residency training position, a requirement to become licensed [5].

With current Medicare funding of teaching hospitals and the cap on the number of GME positions it will cover does not make sense since there is no surplus of physicians [5]. Therefore, raising the number of residency positions supported by Medicare would be appropriate. To avoid further recruitment of foreign graduates from developing countries, Medicare should increase funded positions only to the extent necessary to accommodate the increase in U.S. medical graduates [6].

Developing a system to allocate the increase among teaching hospitals and residency programs would be needed if the policy makers decide on raising the cap for funds rather than eliminating it. Therefore, the US has to plan ahead and set policies in place to depend on its own physician's workforce or else it would be putting the nation at risk for its inability to provide care for the million Medicare beneficiaries who have high exceptions of the health care system [6].

When looking to the increased financial challenges facing hospitals, this might translate into a slow growth in GME positions. Additionally the GME have to cater for the ACGME residency program and in order to do so, GME have to reduce the number of international applicants (IMGs) to cater for its own citizens and demand. Data from the AAMC's GMETrack, the Medical College Admission Test, the National Resident Matching Program, and the Educational Commission for Foreign Medical Graduates, shows that the number of schools in the Caribbean has nearly quadrupled in the past decade, and more than 2,500 U.S. citizens are going out of the United States for medical education every year [7] .

Conversely, U.S. medical schools are starting to increase enrollment of foreign graduates in response to the growing concerns with physician shortages [7]. However, if funding for residency training is not increased, then teaching hospitals may use the increase in U.S. graduates to reduce their reliance on IMGs. It is of note to remember that IMGs make up $25 \%$ of all new physicians entering residency training in the United States each year [7].

The National Council on Graduate Medical Education (COGME) recommended an increase of 3,000 graduates per year by 2015 , and others recommended a decade ago that IMGs entering GME each year should not exceed $10 \%$ of the number of U.S. medical school graduates, IMGs are now close to $35 \%$ of the number of U.S. graduates entering ACMGE-accredited training programs annually [7].

This dependency on foreign-trained physicians at a rate higher than is healthy for the United States U.S is good if it is looked at as a mean to improve international health rather than viewing it as a way to recruit foreign physicians. This dependency will eventually brain drain the developing world of its valuable human resources, physicians [8].

Furthermore, dependence on foreign-trained physicians hinders the progress of the US national public health infrastructure. This is to say, that recruiting foreigners to fulfill the gap, rather than working on strategies to find alternative solutions is a threat to the US national public health infrastructure that will only grow worse in the coming decades as we compete with other expanding economies for these valuable resources [8]. The failure of the United States to train its own physician workforce puts the nation at risk of being unable to provide adequate care for millions of individuals [8].

This overlooked serious problem could be taken as an opportunity to improve medical education and training and increase their efficiency, to bring new and diverse types of people to medicine, to address medical education and training financing, and to reduce the brain drain from poorer countries.

It is prudent to address the physicians' shortage crisis early before waiting after 25 years to miss on solutions to a problem that has become evident; i,e proper planning for developing policies and acting upon them form now to address 
the physicians workforce. Some studies conducted have shown that international medical graduates do help serve in rural and undeserved areas which in turn help solve a problem of physicians' shortage particularly in those areas and can aid in reducing the misdistribution of services among different states [8.

The benefits that can arise from recruiting the IMGs help in filing in the gaps of the physicians' shortage on a local level in the US [9]. Additionally, this might increase the level and quality of care provided in the exporting countries. This would be explained by the temporary migration of some IMGs who can transfer scientific knowledge, technology and new techniques to their national country that had been attained from the US [9]. Some benefits arise from migration as well. Reliance on IMGs might pose a problem on the quality of the health service provided in the US, since their training programs might not be well aligned with the local disease patterns and not of adequate strength [9].

The IMGs coming from developing countries will face losses of highly skilled professionals in addition to financial losses related to their investment into these professionals in terms of education and training.The loss of highly skilled personnel can further affect future generations of professionals, as many academics are among those who leave the country [9].

It has yet to be remembered, that there are barriers that might face the IMGs, one of which is the low pass rates of the ECFMG exams. Let's also remember the increased litigations that physicians face in certain specialties like surgery and obstetrics have led many physicians away from this practice thus leading to a skew of services in certain fields of medicine. However, recruiting more IMGs might help solve this skew [10].

\section{Conclusion}

As paradoxical as it might seem policy makers, legislators, medical educators, and academics have to recognize that the United States is permanently involved in international exchange and is a sought after destination for immigrants of all occupations [11].
It is unreasonable to think that the dependency on IMGs should be closed off; rather it has to be looked that IMGs will continue to be a requirement for the important contributions it might contribute in medicine for the US citizens and for themselves and their nations. It may be more reasonable to say that strong efforts has to be made for future training of thousands of IMGs who are currently and probably in future will continuously migrate to the US. Therefore it is mandatory that US health policy makers acknowledge the role that IMGs have made in the past and design an infrastructure that maintains and recruits IMGs for both the benefit of the patients and the providers.

\section{References}

1. http://www.massmed.org/AM/Template.cfm?Section=MMS_News Releases\&CONTENTID=31507\&TEMPLATE=/CM/ContentDisplay.cfm

2. Schofield DJ (2007) Replacing the projected retiring baby boomer nursing cohort 2001-2026. BMC Health Serv Res 7: 87.

3. Health Resources and Services Administration Bureau of Health Profession (2008) “The Physician Workforce: Projections and Research into Current Issues Affecting Supply and Demand," U.S. Department of Health and Human Services.

4. https://www.bls.gov/ooh/healthcare/physicians-and-surgeons.htm.

5. http://www.ama-assn.org/amednews/m/2012/05/21/psc0522.htm

6. https://www.aamc.org/download/82874/data/helpwanted.pdf

7. Rich E, Liebow M, Srinivasan M, Parish D, Wolliscroft J, Fein O, et al. (2002) Medicare Financing of Graduate Medical Education. Intractable Problems, Elusive Solutions J Gen Intern Med. 17(4): 283-292.

8. Ranasinghe PD (2015) International medical graduates in the US physician workforce. J Am Osteopath Assoc 115(4): 236-241.

9. Salsberg E, Grover A (2006) Physician Workforce Shortages: Implications and Issues for Academic Health Centers and Policymakers. Acad Med; 81(9): 782-787.

10. Baer LD, Ricketts TC, Konrad TR, Mick SS (1998) Do International Medical Graduates Reduce Rural Physician Shortages? Medical Care ; 36(11): 1534-1544.

11. Mick S (1993) Foreign medical graduates and U.S. physician supply: old issues and new questions. Health Policy ; 24(3): 213-225.

\section{Your next submission with Juniper Publishers} will reach you the below assets

- Quality Editorial service

- Swift Peer Review

- Reprints availability

- E-prints Service

- Manuscript Podcast for convenient understanding

- Global attainment for your research

- Manuscript accessibility in different formats

( Pdf, E-pub, Full Text, Audio)

- Unceasing customer service

Track the below URL for one-step submission https://juniperpublishers.com/online-submission.php 